\title{
Glomerulonephritis with crescents in childhood; etiologies and significance of M2 macrophages
}

\author{
Gözdem Kayk1 ${ }^{1 \oplus}$, Diclehan Orhan ${ }^{2 \oplus}$, Bora Gülhan ${ }^{3 \oplus}$, Rezan Topaloğlu ${ }^{3 \oplus}$, \\ Zuhal Akçören ${ }^{2 \odot}$, Ali Düzova ${ }^{3 \odot}$, Fatih Özaltın ${ }^{3 \oplus}$, Seza Özen ${ }^{4 \oplus}$, Yelda Bilginer ${ }^{4 \oplus}$, \\ Şafak Güçer ${ }^{2 \odot}$
}

Divisions of ${ }^{2}$ Pediatric Pathology, ${ }^{3}$ Pediatric Nephrology and ${ }^{4}$ Pediatric Rheumatology, ${ }^{1}$ Department of Pediatrics, Hacettepe University Faculty of Medicine, Ankara, Turkey.

\begin{abstract}
Background. Crescentic glomerulonephritis (CGN) is a rapidly progressive and rare cause of glomerulonephritis in childhood. The aim of this study is to evaluate demographic data of children with crescentic glomerulonephritis, to classify the etiologies and to investigate the correlation between the severity of kidney disease and the expression of CD163+ macrophages.

Methods. Between the years 2000 and 2016 in a single center, patients under 18 years of age with kidney biopsies containing crescents were included in the study. A total of 88 children were enrolled. The expression of CD163 in kidney tissues was detected by immunohistochemistry in 61 patients. Clinical features and outcome were collected from their medical records.

Results. The most common etiology was Henoch-Schönlein purpura (HSP) nephritis/Immunglobulin A vasculitis $(26.1 \%)$, followed by lupus nephritis $(22.7 \%)$ and idiopathic crescentic glomerulonephritis $(18.2 \%)$. CD163 positive cell counts in patients with GFR levels less and more than $60 \mathrm{ml} / \mathrm{min} / 1.73 \mathrm{~m}^{2}$ at their last visit were $7.6 \pm 6.6$ cells vs. $2.0 \pm 3.0$ cells ( $\mathrm{p}=0.057$ ) per one glomerulus and $52.2 \pm 18.2$ cells/hpf vs. $33.3 \pm 10.0$ cells $/ \mathrm{hpf}$ $(\mathrm{p}<0.05)$ in tubulointerstitium, respectively. Tubulointerstitital CD163+ cells were also found to be higher in patients with end stage kidney disease than complete and partial responders ( 68 cells/hpf vs 39 cells/hpf, $\mathrm{p}<0.05$ ).

Conclusions. CD163 positive cell counts, particularly in tubulointerstitial areas, have been associated with poor prognosis of CGN.
\end{abstract}

Key words: crescentic glomerulonephritis, CD163 macrophages, M2 macrophages.

Crescentic glomerulonephritis (CGN) is a rare entity in childhood. Membranoproliferative glomerulonephritis (MPGN), immunoglobulin A nephropathy (IgAN), Henoch-Schönlein purpura (HSP) nephritis/IgA vasculitis, poststreptococcal glomerulonephritis, lupus

Gözdem Kayk1

gozdem.kayki@hacettepe.edu.tr

Received 14th August 2020, revised 20th March 2021, 21st September 2021, accepted 29th November 2021.

This study was presented in the 8th Europediatrics Congress, 7-10 June 2017, Bucharest, Romania . The abstract was published in Archives of Disease in Childhood 102 (Suppl 2): A3.1-A3. nephritis, polyarteritis nodosa and ANCA associated vasculitis may cause CGN.

A few clinicopathologic data are available in childhood CGN in English literature. Altough the exact mechanism of crescent formation is unclear; it has been thought of as a nonspecific response of the parietal epithelial cells of Bowman capsule against an injury of glomerular capillary wall. Polymorphonuclear neutrophils, lymphocytes $\left(\mathrm{CD}^{+}\right.$and $\mathrm{CD}^{+}$ cells) and macrophages have primary roles in the pathogenesis. ${ }^{1,2}$ Moreover, infiltration of macrophages is a universal characteristics of glomerular injury both in human and experimental studies. ${ }^{3-7} \quad$ Macrophages are 
divided into two groups as M1 and M2 according to the expression of different surface molecules and transcription factors. ${ }^{4}$ M1 macrophages are activated classically, promote $\mathrm{T}$ helper (Th) 1 responses and produce proinflammatory cytokines. ${ }^{8,9}$ Whereas M2 macrophages are activated in alternative way. ${ }^{5}$ They contribute to tissue repair and promote Th2 responses. CD163 is the marker of M2 macrophages and is a member of the cysteine-rich scavenger receptor family. ${ }^{4}$ An experimental study with crescentic glomerulonephritis rat models demonstrated that inflammatory lesions in the first 14 days changed to chronic fibrotic damage while a classically activated proinflammatory M1 phenotype was turning to an alternatively activated M2 phenotype from 14 to 35 days. ${ }^{10}$ In a clinical study related with proliferative glomerulonephritis, CD163 as a marker of M2 was found to be more prominent in crescentic samples, suggesting CD163 involvement in pathogenesis in CGN. ${ }^{4}$ Zhao et al. ${ }^{5}$ also reported that CD68 and CD163 positive cells and polymorphonuclear neutrophils were seen more in glomerulus with crescents than only focal necrotizing glomerulus in patients with pauci immune glomerulonephritis, anti-GBM glomerulonephritis and immune complex induced glomerulonephritis. Additionally, a few clinical studies of proliferative glomerulonephritis suggested a correlation between the disease severity and CD163 positive macrophages infiltration. However, the data regarding the relationship between the prognosis of the crescentic glomerulonephritis and the number of $\mathrm{CD}_{163^{+}}$macrophages (M2) is still scarce.

In this study, we aimed to evaluate the demographic data of 88 children from our center whose kidney biopsies contained crescents, to classify etiologies and to investigate the relation of $\mathrm{CD}_{163^{+}}$macrophage infiltration with disease severity and prognosis. This is the first study to evaluate the relationship between the severity and prognosis of the CGN in childhood and the number of $\mathrm{CD}_{163^{+}}$macrophages.

\section{Material and Methods}

\section{Patients}

A total of 1344 pediatric kidney biopsies between the years 2000 and 2016 at Pediatric Pathology Department, Hacettepe University Faculty of Medicine were reviewed. A total of 88 patients with biopsies containing crescents were included in this study. The data of age, sex, follow-up duration, blood pressure, proteinuria, levels of creatinine, albumin, glomerular filtration rate (GFR), time of biopsy, treatment before biopsy, and outcome were collected from patients' medical records. Estimated GFR was calculated based on serum creatinine levels and height by bedside Schwartz formula. ${ }^{11}$ All biopsy specimens in the study were reevaluated on light microscopy and percentages of crescent, crescent type and fibrosis were recorded. Patients were divided into groups according to the underlying etiology such as $\mathrm{HSP} / \operatorname{IgA}$ vasculitis, lupus nephritis, postinfectious glomerulonephritis, IgA nephropathy, MPGN and pauci-immune glomerulonephritis. If no underlying cause was found, patients were included in idiopathic crescentic glomerulonephritis group.

The control group included 22 patients without crescent (six girls and sixteen boys); 8 of them with minimal change disease, 4 of them with IgA nephropathy and 10 of them with GFR less than $60 \mathrm{ml} / \mathrm{min} / 1.73 \mathrm{~m}^{2}$. The cases that had no crescent with GFR less than $60 \mathrm{ml} /$ $\mathrm{min} / 1.73 \mathrm{~m}^{2}$ included Wegener granolomatosis $(n=1)$, tubulointerstitial nephritis $(n=4)$, lupus nephritis $(n=1)$, juvenile nephronophithisis $(n=3)$ and hemolytic uremic syndrome $(n=1)$. Their mean age was $12.4 \pm 3$ years ( $2-18$ years).

Response of treatment was categorized into four groups.

Complete response: patients with normal physical examination, urinary test, albumin and GFR level at last visit,

Partial response: patients with microscopic hematuria or $24-\mathrm{hr}$ proteinuria $4-40 \mathrm{mg} / \mathrm{m}^{2} / \mathrm{hr}$ at last visit, 
Non-responder: patients with 24-hr proteinuria above $40 \mathrm{mg} / \mathrm{m}^{2} / \mathrm{hr}$ or GFR below $60 \mathrm{ml} /$ $\mathrm{min} / 1.73 \mathrm{~m}^{2}$ but above $15 \mathrm{ml} / \mathrm{min} / 1.73 \mathrm{~m}^{2}$ at last visit,

End stage kidney disease: patients with kidney replacement therapy (dialysis, transplantation), or GFR $15 \mathrm{ml} / \mathrm{min} / 1.73 \mathrm{~m}^{2}$ or below at last visit,

\section{Histopathological analysis}

Kidney biopsies of 61 patients and 22 control biopsies were available for immunohistochemical stainings since paraffin blocks of 27 patients were not sufficient for immunohistochemical staining. Sections from every paraffin block were taken by using Shandon Finesse ME (Thermo Scientific) label microtom and Feather A35 microton knife (Japan) on Histobond + (Mariefeld, German) and Objekttrager (Isotherm, German) adhesive polylysin slide. Two sections were taken from each sample. Sections were dried for one night at room temperature and were hidden until staining. Samples from paraffin blocks were stained with ready-to-use CD163 antibodies in Leica Bond-Max (England) device. For immunohistochemical analysis CD163 positive cells were shown the average number of positive cells in every ten high power glomerular and tubulointerstitial field (hpf, x40). Cells in ten fields were counted and the average was used for analysis. ${ }^{4,12}$ Histopathological analysis was performed by the pathologist who was blinded to the clinical parameters.

\section{Statistical analysis}

The research data were uploaded to a computer and evaluated by Statistical Package for Social Sciences (SPSS) for Windows 22.0 (SPSS Inc, Chicago, IL). Descriptive statistics were presented as frequency distribution and percentage. Frequency distributions and percentages for categorical variables were given as basic descriptive statistics such as mean, standard deviation, median, minimum, maximum for quantitative variables. Repeated measures ANOVA was applied to the measurements in order to analyze the timedependent changes of the repeated measures. LSD test was applied in order to be able to determine which measure is different when there was a statistically significant difference $(p<0.05)$ between the means of the repeated measures in the result of the analysis.

Non-parametric Mann-Whitney U Test, parametric independent samples $\mathrm{t}$ test, Chisquare analysis, Tamhane's T test were used. For correlation analysis, Spearman correlation coefficient between the variables was given as the result of analysis.

This study was approved by the Ethical Committee of Hacettepe University (GO 15/75529). This study was supported by the Scientific Research Unit of Hacettepe University (THD2016-8972).

\section{Results}

Kidney biopsies of 88 patients with crescents between the years 2000-2016 and 22 controls were included in the study. There were 40 girls (45.5\%) and 48 boys (54.5\%) in the patients' group. The mean age of the patients was 11.49 \pm 3 years at the time of biopsy. There were six girls and sixteen boys in the control group and their mean age was $12.4 \pm 3$ years $(p=0.363)$. At the time of biopsy, proteinuria and hematuria were detected in $100 \%$ and $85 \%$ of patients, respectively. The median duration from the onset of clinical findings to kidney biopsy was 42 days (IQR 20-120).

Seventy percent of the patients received steroid, immunosuppressive or immunomodulation treatment before biopsy.

\section{Etiology}

The most common underlying etiology was $\mathrm{HSP} / \mathrm{Ig}$ A vasculitis (26.1\%), followed by lupus nephritis $(22.7 \%)$ and idiopathic CGN (18.2\%) (Fig. 1). Idiopathic CGN was defined if no underlying cause was found. 


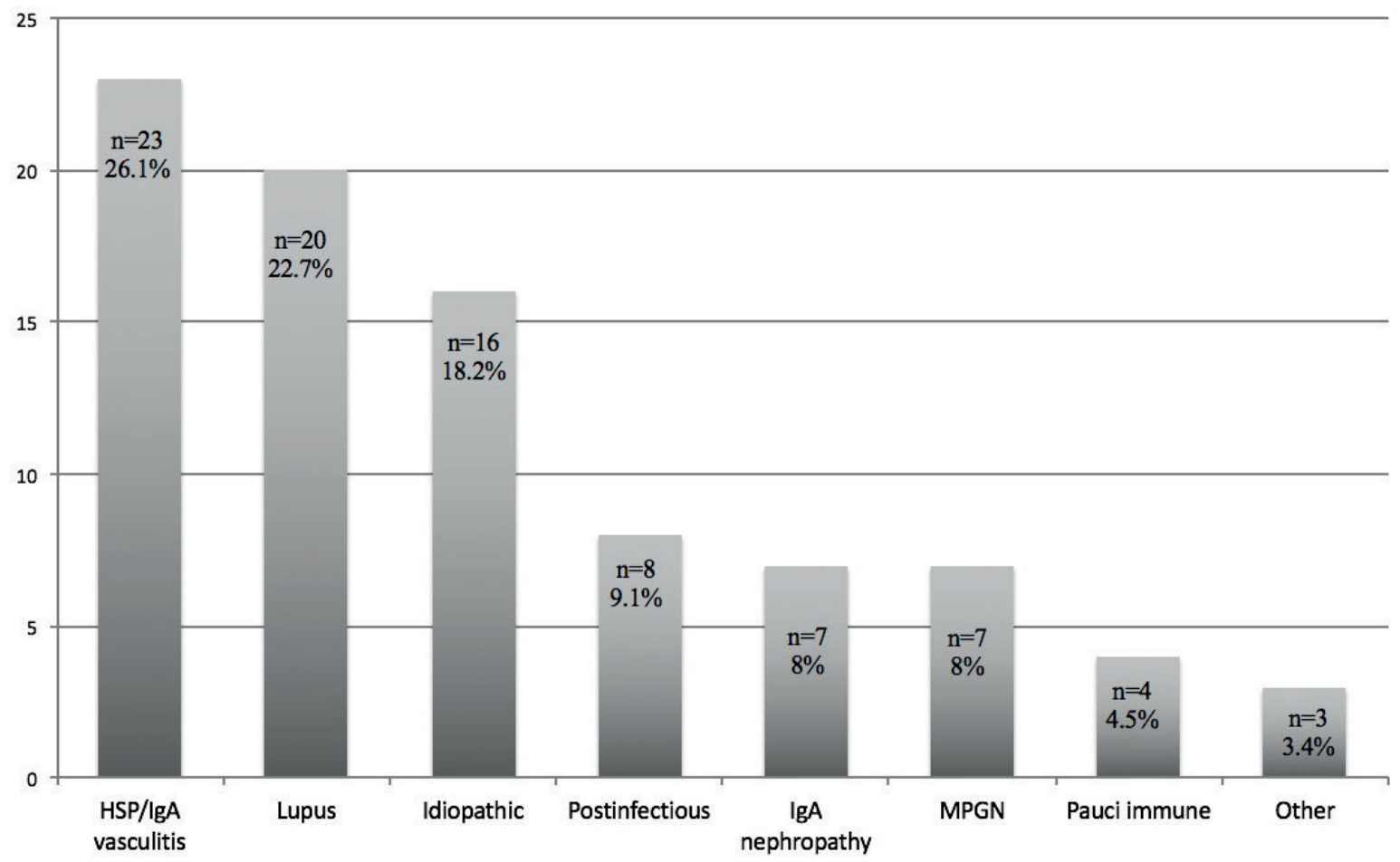

Fig. 1. Classification of cresentic glomerulonephritis according to the etiology. Others included one patient with C3 glomerulonephritis, one with chronic pyelonephritis and an Alport syndrome.

\section{Prognosis}

The outcome data of 70 patients were available. Mean follow-up duration of these 70 patients was $3.2 \pm 3$ years. At last visit; $52 \%(n=36)$ was complete responder, $17 \%(\mathrm{n}=12)$ was partial responder, $14 \% \quad(\mathrm{n}=10)$ was non-responder and $17 \%(n=12)$ was end-stage kidney disease. During follow-up, four patients had kidney transplants and two patients who were administered hemodialysis died of sepsis. Underlying kidney diseases of four patients who underwent kidney transplants included lupus nephritis (one patient), dense deposit disease (one patient) and idiopathic crescentic glomerulonephritis (two patients). One patient with MPGN and one patient with pauci immun glomerulonephritis died of sepsis.

\section{Crescents}

All biopsy specimens in the study were reevaluated by light microscopy. There were cellular, fibrocellular and fibrous crescents in $70.5 \%, 27.2 \%$ and $2.3 \%$ of the patients, respectively. The mean crescent percentage was $38.9 \%$ (min. $2.8 \%$, max. $100 \%$ ) and $30.7 \%$ patients (27/88) had crescents more than $50 \%$. Seventy patients $(79.5 \%)$ had partial crescent formation and other 18 patients $(20.5 \%)$ had global crescent formation.

The relationship between crescent percentage and the outcome were evaluated (Fig. 2). Patients with crescents less than $50 \%$ had more complete and partial responder rates compared to patients with crescents more than $50 \%$. Cases with crescents more than $50 \%$ had more endstage kidney disease compared to ones with crescents less than $50 \%[8 / 20(40 \%)$ vs. $4 / 50$ $(8 \%) ; \mathrm{p}<0.05]$.

\section{Immunohistochemical staining}

Biopsy specimen of 22 controls and 61 patients were stained with CD163 (Figs 3 and 4). Patients in the control group had no crescent formation. The control group was divided 


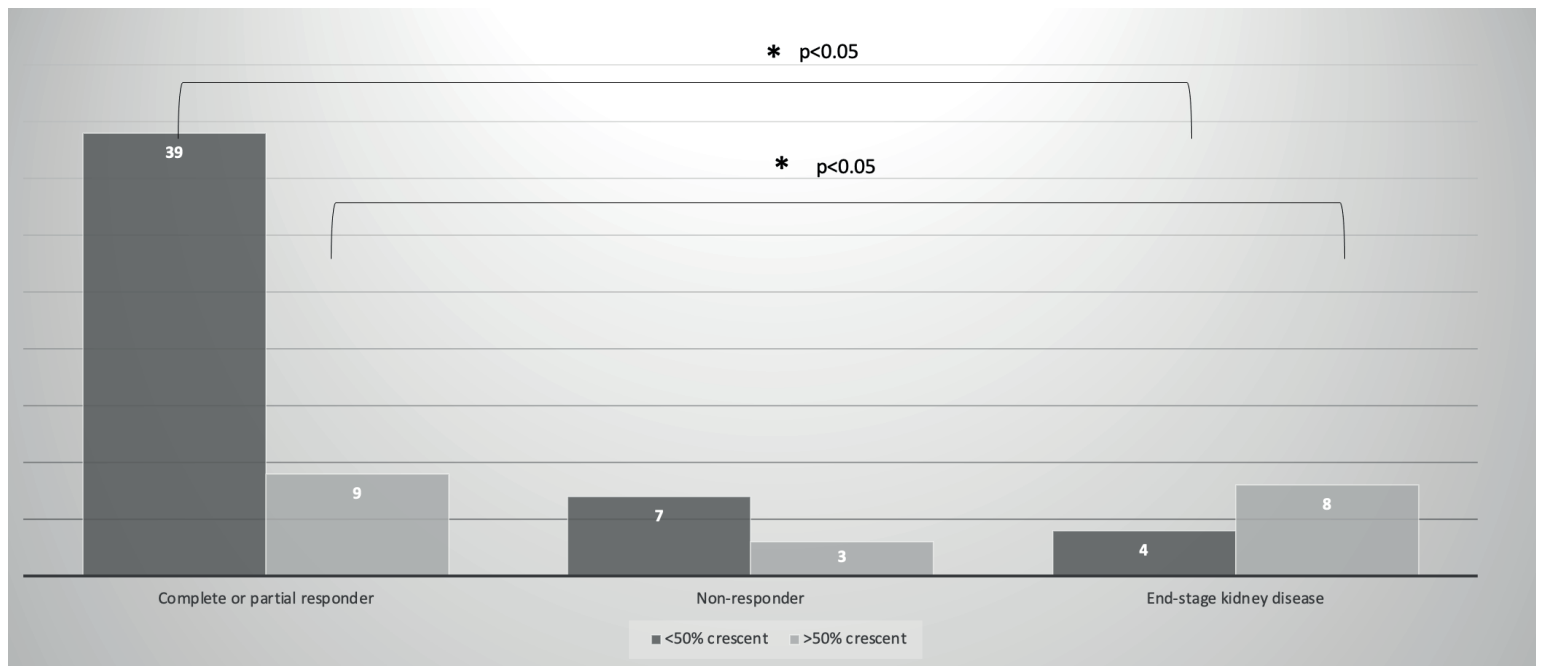

Fig. 2. Relationship between crescent percentage and the outcome. $\left({ }^{*}\right.$ demonstrates statistically significant difference between two groups).

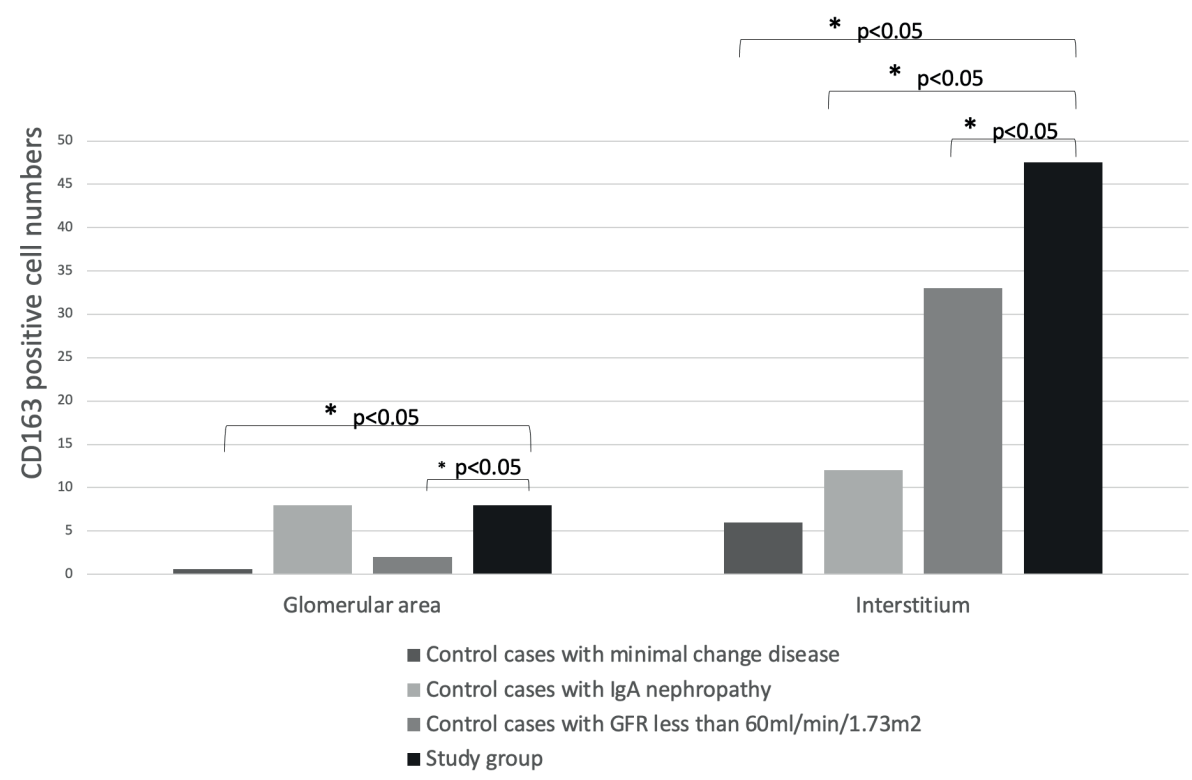

Fig. 3. CD163 + cells' counts of study and control groups. ( ${ }^{*}$ demonstrates statistically significant difference between two groups).

into three subgroups and each group was compared with the patients individually. While comparing the results, patients with crescentic glomerulonephritis had a higher number of CD163+ macrophages than the controls $(p<0.05)$ except the glomerular area of the controls with $\operatorname{IgA}$ nephropathy. Controls with $\operatorname{IgA}$ nephropathy had the same amount of CD163+ macrophages as all patients with crescentic glomerulonephritis.
Immunohistopathological stainings of the patients with different etiologies are given in Table I. While comparing every etiologic group with each other, no difference in CD163 staining of glomerulus and tubulointerstitium was found ( $\mathrm{p}=0.26, \mathrm{p}=0.12$, respectively).

The relationship between CD163 and crescent percentage (less or more than $50 \%$ crescent), GFR levels at their last visit (less or more 

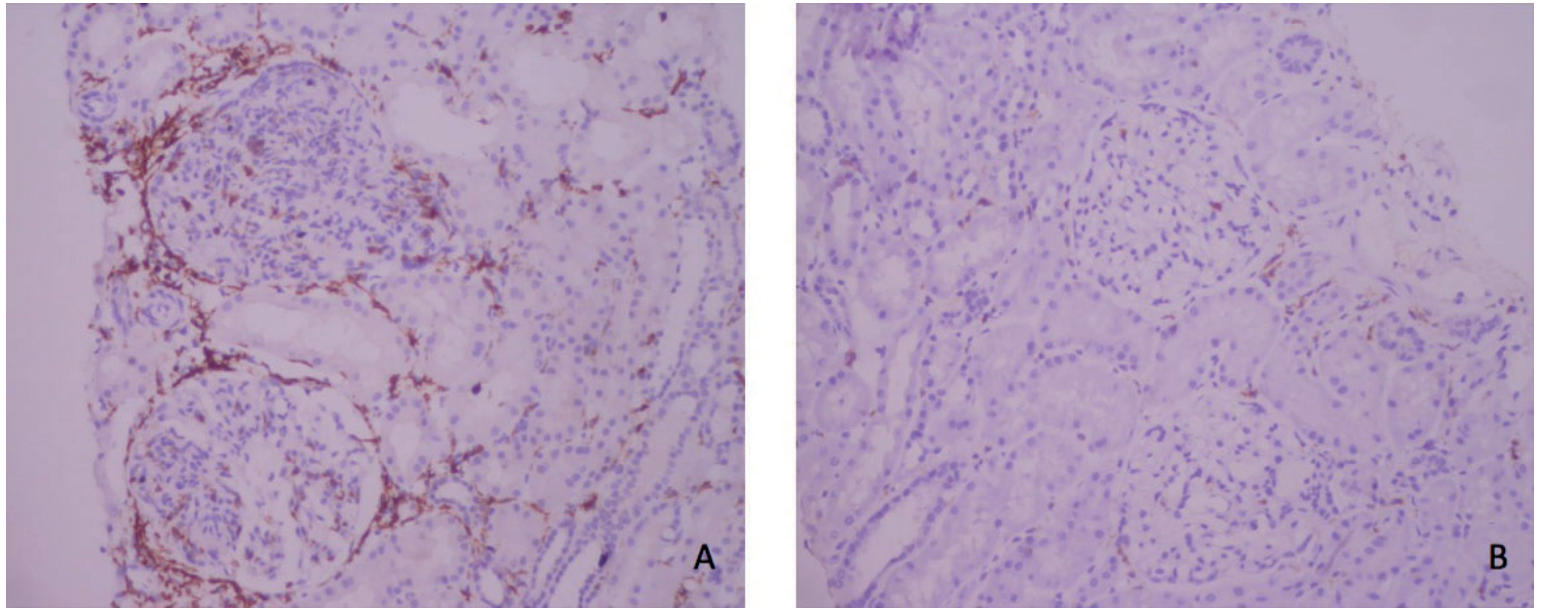

Fig. 4. A) CD163 staining in both glomerulus and tubulointerstitium in a patient with lupus nephritis. (Immunohistochemistry x200) B) CD163 staining of a patient in the control group (Immunohistochemistry x200).

Table I. CD163 positive cell counts in glomerulus (G) and tubulointerstitium (TI) according to the etiologies.

\begin{tabular}{llllll}
\hline Marker & Tissue compartment & IC mediated (MPCC) & Pauci immune (MPCC) & Others (MPCC) & p \\
\hline \multirow{2}{*}{ CD163 } & Glomerulus & 8.38 & 13.5 & 3.2 & 0.26 \\
& Tubulointerstitium & 46.74 & 57.5 & 58.1 & 0.12 \\
\hline
\end{tabular}

*IC: immune complex, MPCC: mean positive cell count

than $\left.60 \mathrm{ml} / \mathrm{min} / 1.73 \mathrm{~m}^{2}\right)$, and the percentage of fibrosis $(<5 \%, 5-25 \%, 25-50 \%,>50 \%)$ were investigated (Table II). There was a statistically significant increase in tubulointerstitial CD163 positive macrophages in patients with GFR levels less than $60 \mathrm{ml} / \mathrm{min} / 1.73 \mathrm{~m}^{2}$ at the last visit $(52.2 \pm 18.2$ cells/hpf vs. $33.3 \pm 10$ cells/hpf, $\mathrm{p}<0.05$ ). Additionally, there were significantly more CD163 positive cells in tubulointerstitial areas of patients who had fibrosis higher than $50 \%(\mathrm{p}<0.05)$.

Treatment protocols were available in 78 patients. Among these, 69.3\%, 19.3\% and $34.1 \%$ received pulse steroid, azathioprine and cyclophosphamide, respectively. Rituksimab (5 patients) and cyclosporine (5 patients) were also given. Dialysis was needed in $19.3 \%$ patients.

Patients were classified into four groups (complete responder, partial responder, nonresponder and end-stage kidney disease) at last visit according to the outcome. Patients with end-stage kidney disease had statistically significant more CD163 positive cells in tubulointerstitium compared to the patients with complete and partial response $(p<0.05)$ (Table II).

\section{Discussion}

Crescentic glomerulonephritis is a rare entity in childhood. In this study, 88 children with kidney biopsies with crescents were evaluated for clinical and histopathological characteristics. The relationship between the disease severity and the number of CD163 positive macrophages was investigated for 61 patients.

The mean age of the patients at the time of biopsy was $11.49 \pm 3$ years which is similar to other pediatric crescentic glomerulonephritis series with the mean ages ranging from 10 to 12.27 years. ${ }^{13-15}$

The most common etiologic cause in our cohort was HSP nephritis/IgA vasculitis followed by lupus nephritis and idiopathic CGN. The 
Table II. CD163 positive cell counts in glomerulus (G) and tubulointerstitium (TI) according to crescent percentage, GFR levels and fibrosis percentage.

\begin{tabular}{|c|c|c|c|}
\hline \multicolumn{2}{|l|}{ Parameters } & $\begin{array}{c}\text { Glomerulus } \\
\text { CD163 }^{+} \text {cells } / \mathrm{hpf}\end{array}$ & $\begin{array}{l}\text { Tubulointerstitium } \\
\text { CD163 }{ }^{+} \text {cells/hpf }\end{array}$ \\
\hline \multirow[t]{3}{*}{ Crescent percentage } & $<50 \%$ & 8.2 & 45.1 \\
\hline & $>50 \%$ & 7.8 & 57.5 \\
\hline & $\mathrm{p}$ & 0.18 & 0.54 \\
\hline \multirow[t]{3}{*}{ GFR levels } & $>60 \mathrm{ml} / \mathrm{min} / 1.73 \mathrm{~m}^{2}$ & 2 & 33.3 \\
\hline & $<60 \mathrm{ml} / \mathrm{min} / 1.73 \mathrm{~m}^{2}$ & 7.6 & 52.2 \\
\hline & $\mathrm{p}$ & 0.06 & $<0.05$ \\
\hline \multirow[t]{3}{*}{ Fibrosis percentage } & $<50 \%$ & 8.2 & 42.5 \\
\hline & $>50 \%$ & 9.3 & 67.3 \\
\hline & $\mathrm{p}$ & 0.79 & $<0.05$ \\
\hline \multirow[t]{3}{*}{ Treatment response } & Complete or partial responder & 8.5 & 39.2 \\
\hline & End-stage kidney disease & 2.3 & 68.1 \\
\hline & $\mathrm{p}$ & 0.16 & $<0.05$ \\
\hline
\end{tabular}

etiologic causes of CGN in children and adults have been known to be different. According to the study covering 528 adult patients from China, the most common etiology was pauci immune GN. It was also the most common etiology in series from USA, India, Japan and Spain $(60 \%$, $72 \%, 64 \%$ and $67.2 \%$, respectively). ${ }^{12,13,16-18}$ Jennette et al. ${ }^{12}$ divided patients with CGN into groups according to their ages and stated that the most common etiology was immune complex mediated glomerulonephritis in patients younger than 20 years. The incidence of pauci immune glomerulonephritis was $42 \%$ and its incidence increased with age. The childhood series from other countries reported immune complex mediated glomerulonephritis as the most common etiology, as well. ${ }^{14}$ Ozlu et al. ${ }^{15}$ reported that the most common etiology was HSP nephritis/IgA vasculitis (24 out of 45 patients) followed by idiopathic CGN (9/45) similar to our study.

HSP nephritis/IgA vasculitis which was the leading etiology in our study, has also been the most common vasculitis in childhood in our country. ${ }^{15,19}$ It was reported to be the underlying cause in $10-15 \%$ of childhood glomerulonephritis and $3 \%$ of the end-stage kidney disease. ${ }^{20}$
The mean crescent percentage was $38.9 \%$ with predominant cellular crescents $(70.5 \%)$ and total $30.7 \%$ patients had crescents more than $50 \%$ in our study. Southwest Pediatric Nephrology Study Group reported the mean crescent percentage as $63 \%$ with the majority of fibrous/fibrocelular crescents. ${ }^{21}$ Piyaphanee et al. ${ }^{22}$ studied 67 patients with RPGN and $31.1 \%$ of them had crescents more than 50\% similar to our study. As far as the relationship between crescent percentage and the outcome is concerned, the patient group with less than $50 \%$ crescent percentage had more patients with complete and partial response at the last visit compared to the patient group with crescents higher than 50\%. Besides, patients with crescent precentage more than $50 \%$ had more end-stage kidney disease at last visit. This finding is compatible to the other studies in the literature. ${ }^{21}$ It supports that higher percentage of crescents is related with worse outcome.

In the present study, complete responders were $51.4 \%$ while partial responders $17.2 \%$, irrespective of etiology. The incidence of chronic kidney disease seemed fewer than another center in our country $(17.2 \%$ vs. $42.2 \%) .{ }^{15}$ However, they included only patients with crescents more than $50 \%$ while we included all 
patients with crescents. It may have explained the discrepancy of this outcome, since we also found that the incidence of end-stage kidney disease was $40 \%$ in patients with crescents more than $50 \%$. Two patients died in the end-stage kidney disease's group. One of these patients suffered pauci immune glomerulonephritis and the other had MPGN.

Patients with end-stage kidney disease had statistically significant more CD163 positive cells in tubulointerstitium than patients with complete and partial responders. $\mathrm{CD} 163^{+}$ macrophages were found in areas of renal fibrosis and also showed that they produce profibrotic factors in previous studies. ${ }^{23,24}$ In this study, CD163 staining was found higher in the samples with higher fibrosis percentage, as well. This fibrotic process may be the reason for the worse outcome. A previous study supporting these findings was reported by Li et al. ${ }^{4}$ The clinicopathologic importance of CD163 was evaluated in the study on adult patients with proliferative glomerulonephritis. They reported that CD163 staining in the tubulointerstitium was positively correlated with proteinuria and negatively correlated with albumin. ${ }^{6}$ In their another study related with glomerulonephritis with crescents, they observed $\mathrm{CD} 163^{+}$cells were correlated with the percentage of crescent in all areas, but the $\mathrm{CD} 163^{+}$ cells and GFR relationship was only found in the tubulointerstitial area. ${ }^{25}$ These findings supported our data and also demonstrated the clinicopathological importance of CD163. The number and percentage of CD163 positive cells in tubulointerstitium was found to be higher in patients with crescents above $50 \%$ compared to the patients with crescents below $50 \%$. Besides, the relationship between CD163 positive cell counts and outcome was statistically significant in the tubulointerstitial area, as well. These findings suggest that CD163 positive cells may play a role in tubulointerstitial injury in CGN patients in addition to the response to oxidative stress. Similarly, it was also shown that prominent expression of cytokines was observed in the interstitium of patients with lupus nephritis and in HSP/IgA vasculitis, the Th cytokines were stained in tubular area, as well. ${ }^{26,27}$

On the other hand, Li et al. ${ }^{4,6}$ also found that CD163 staining in glomerulus was positively correlated with proteinuria and negatively correlated with GFR and albumin. In our study, CD163 positive cell counts and outcome were not found to be related in the glomerular areas. Ikezumi et al. ${ }^{28}$ reported the histologic differences between children and adults in new-onset IgA nephropathy. They reported glomerular matrix expansion was found to be more severe in adults than children. ${ }^{28}$ They investigated activated sialoadhesin ( $\mathrm{Sn}$ ) positive macrophages and found that $\mathrm{Sn}+$ macrophages in glomerulus was correlated with glomerular matrix and kidney function in adults, but not in children. Since this finding may account for the different behavior of the local macrophages between adults and children in these cases. It can also be a reason of why there was a correlation between the $\mathrm{CD}_{163}{ }^{+}$cell count and prognosis in glomerular area in adults but not in our pediatric cases.

Patients with crescentic glomerulonephritis had higher number of $\mathrm{CD} 163^{+}$macrophages than the controls $(p<0.05)$ except the glomerular area of the controls with IgA nephropathy. However, a previous study compared IgAN without crescents and IgAN patients with crescents and demonstrated higher numbers of CD163 positive cells in both tubulointerstitial lesions and glomerulus in the crescentic disease. ${ }^{6}$ The reason why the difference of glomerular CD163 positive cells in between controls with $\operatorname{IgA}$ nephropathy and the study group could not be shown may be related with the small control group size in the study.

The other limitations of this study were the lack of sufficient kidney tissue in some cases and information including treatments and the small size of samples in each group. Another limitation was the semiquantitative nature of immunohistochemical staining and long time period after the biopsy. After 3 years, 
immunostaining of antigens may not be sufficient.

In conclusion, HSP nephritis was found to be the most common cause of crescentic glomerulonephritis in childhood in this study. Having crescents more than $50 \%$ has a negative affect on the outcome. Histopathological and immunohistochemical findings have supported that CD163 positive M2 type macrophages, especially in tubulointerstitial areas, may have a negative effect on prognosis of CGN. Experimental animal models and clinical investigations to further elucidate the effect of CD163 positive macrophages on the pathogenesis and prognosis of CGN are warranted.

\section{Ethical approval}

This study was approved by the Ethical Committee of Hacettepe University (GO 15/75529).

\section{Author contribution}

The authors confirm contribution to the paper as follows: study conception and design: S. Gucer, G. Kayki, D. Orhan, Z. Akcaoren; data collection: G. Kayki, B. Gulhan, R. Topaloglu, A. Duzova, F. Ozaltin, S. Ozen, Y. Bilginer, S. Gucer; analysis and interpretation of results: G. Kayki, S. Gucer, B. Gulhan, R. Topaloglu; draft manuscript preparation: G. Kayki, S. Gucer, B. Gulhan, R. Topaloglu, D. Orhan. All authors reviewed the results and approved the final version of the manuscript.

\section{Source of funding}

This study was supported by the Scientific Research Unit of Hacettepe University (THD2016-8972).

\section{Conflict of interest}

The authors declare that there is no conflict of interest.

\section{REFERENCES}

1. Atkins RC, Holdsworth SR, Glasgow EF, Matthews FE. The macrophage in human rapidly progressive glomerulonephritis. Lancet 1976; 1: 830-832. https:// doi.org/10.1016/S0140-6736(76)90480-3

2. Chen A, Lee K, Guan T, He JC, Scholondorff D. Role of CD8+ T cells in crescentic glomerulonephritis. Nephrol Dial Trans 2020; 35: 564-572. https://doi. org/10.1093/ndt/gfz043

3. Holdsworth SR, Neale TJ, Wilson CB. Abrogation of macrophage-dependent injury in experimental glomerulonephritis in the rabbit. Use of an antimacrophage serum. J Clin Invest 1981; 68: 686-698. https://doi.org/10.1172/JCI110304

4. Li J, Liu CH, Xu DL, Gao B. Clinicopathological significance of CD 163 positive macrophages in patients with proliferative glomerulonephritis. Am J Med Sci 2015; 350: 387-392. https://doi.org/10.1097/ MAJ.0000000000000569

5. Zhao L, David MZ, Hyjek E, Chang A, Meehan SM. M2 macrophage infiltrates in the early stages of ANCA-associated pauci-immune necrotizing GN. Clin J Am Soc Nephrol 2015; 10: 54-62. https://doi. org/10.2215/CJN.03230314

6. Li J, Liu CH, Gao B, Xu DL. Clinical-pathologic significance of CD163 positive macrophage in IgA nephropathy patients with crescents. Int J Clin Exp Med 2015; 8: 9299-9305.

7. Erwig LP, Kluth DC, Rees AJ. Macrophage heterogeneity in renal inflammation. Nephrol Dial Transplant 2003; 18: 1962-1965. https://doi. org/10.1093/ndt/gfg313

8. Barros MHM, Hauck F, Dreyer JH, Kempkes B, Niedobitek G. Macrophage polarisation: an immunohistochemical approach for identifying M1 and M2 macrophages. PloS One 2013; 8: e80908. https://doi.org/10.1371/journal.pone.0080908

9. Williams TM, Little MH, Ricardo SD. Macrophages in renal development, injury and repair. Semin Nephrol 2010; 30: 255-267. https://doi.org/10.1016/j. semnephrol.2010.03.011

10. Han Y, Ma FY, Tesch GH, Msnthry CL, NikolicPaterson DJ. Role of macrophages in the fibrotic phase of rat crescentic glomerulonephritis. Am J Physiol Renal Physiol 2013; 304: F1043-F1053. https://doi.org/10.1152/ajprenal.00389.2012

11. Schwartz GJ, Munoz A, Schneider MF, et al. New equations to estimate GFR in children with CKD. J Am Soc Nephrol 2009; 20: 629-637. https://doi. org/10.1681/ASN.2008030287

12. Jennette JC. Rapidly progressive crescentic glomerulonephritis. Kidney Int 2003; 63: 1164-1177. https://doi.org/10.1046/j.1523-1755.2003.00843.x 
13. Lopez-Gomez JM, Rivera F; Spanish Registry of Glomerulonephritis. Renal biopsy findings in acute renal failure in the cohort of patients in the Spanish Registry of Glomerulonephritis. Clin J Am Soc Nephrol 2008; 3: 674-681. https://doi.org/10.2215/ CJN.04441007

14. Dewan D, GulatiS, Sharma RK, etal. Clinical spectrum and outcome of crescentic glomerulonephritis in children in developing countries. Pediatr Nephrol 2008; 23: 389-394. https://doi.org/10.1007/s00467-0070647-3

15. Ozlu SG, Caltık A, Aydog O, et al. Crescentic glomerulonephritis in children: a single centre experience. World J Pediatr 2016; 12: 225-230. https:// doi.org/10.1007/s12519-015-0036-0

16. Chen S, Tang Z, Xiang H, et al. Etiology and outcome of crescentic glomerulonephritis from a single center in China: a 10-year review. Am J Kidney Dis 2016; 67: 376-383. https://doi.org/10.1053/j.ajkd.2015.07.034

17. Gupta R, Singh L, Sharma A, Bagga A, Agarwal SK, Dinda AK. Crescentic glomerulonephritis: a clinical and histomorphological analysis of 46 cases. Indian J Pathol Microbiol 2011; 54: 497-500. https://doi. org/10.4103/0377-4929.85081

18. Koyama A, Yamagata K, Makino H, et al. A nationwide survey of rapidly progressive glomerulonephritis in Japan: etiology, prognosis and treatment diversity. Clin Exp Nephrol 2009; 13: 633-650. https://doi.org/10.1007/s10157-009-0201-7

19. Stewart M, Savage JM, Bell B, McCord B. Long term renal prognosis of Henoch-Schönlein purpura in an unselected childhood population. Eur J Pediatr 1988; 147: 113-115. https://doi.org/10.1007/BF00442205

20. Niaudet P, Habib R. Schönlein-Henoch purpura nephritis: pronostic factors and therapy. Ann Med Interne (Paris) 1994; 145: 577-580.
21. Hogg RJ. A Clinico-pathologic study of crescentic glomerulonephritis in 50 children. A report of the Southwest Pediatric Nephrology Study Group. Kidney Int 1985; 27: 450-458. https://doi.org/10.1038/ ki.1985.30

22. Piyaphanee N, Ananboonatrick C, Supavekin S, Sumboonnanonda A. Renal outcomes and risk factors for ESRD in children with rapidly progressive glomerulonephritis. Pediatr Int 2017; 59: 334-341. https://doi.org/10.1111/ped.13140

23. Ikezumi Y, Suzuki T, Karasawa T, et al. Identification of alternatively activated macrophages in newonset paediatric and adult immunoglobulin A nephropathy: potential role in mesangial matrix expansion. Histopathology 2011; 58: 198-210. https:// doi.org/10.1111/j.1365-2559.2011.03742.x

24. Nikolic-Paterson DJ, Wang S, Lan HY. Macrophages promote renal fibrosis through direct and indirect mechanism. Kidney Int Suppl 2014; 4: 34-38. https:// doi.org/10.1038/kisup.2014.7

25. Li J, Yu YF, Liu CH, Wang CM. Significance of M2 macrophages in glomerulonephritis with crescents. Pathol Res Pract 2017; 213: 1215-1220. https://doi. org/10.1016/j.prp.2017.04.011

26. Gulhan B, Orhan D, Kale G, Besbas N, Ozen S. Studying cytokines of $\mathrm{T}$ helper cells in the kidney disease of $\operatorname{IgA}$ vasculitis (Henoch-Schönlein purpura). Pediatr Nephrol 2015; 30: 1269-1277. https://doi.org/10.1007/s00467-015-3051-4

27. Yazıcı MU, Orhan D, Kale G, Besbas N, Ozen S. Studying IFN-gamma, IL-17 and FOXP3 in pediatric lupus nephritis. Pediatr Nephrol 2014; 29: 853-862. https://doi.org/10.1007/s00467-013-2695-1

28. Ikezumi Y, Suzuki T, Imai N, et al. Histological diffences in new-onset IgA nephropathy between children and adults. Nephrol Dial Transplant 2006; 21: 3466-3474. https://doi.org/10.1093/ndt/gfl455 